\title{
El lenguaje inconcluso de la arquitectura marginal peruana. Una visión contrastada entre la globalización y el habitar
}

\author{
Gonzalo Ríos Vizcarra \\ Universidad Católica de Santa María de Arequipa \\ Recibido: 17 de julio del 2018 / Aprobado: 23 de agosto del 2018 \\ doi: 10.26439/limaq2019.n005.4531
}

Todo lenguaje, incluido el arquitectónico, se crea para que un grupo lingǘstico sea capaz de compartir una narrativa que estructure algún tipo de realidad. Deteniéndonos en el caso de la arquitectura popular contemporánea en el Perú, el presente texto propone ahondar en las coordenadas espaciotemporales actuales, en las cuales las creaciones tendrán validez, y determinar las escalas de valores vigentes en cuyos podios estos habitantes priorizan sus requerimientos y los convierten en productos estéticos. A partir de ello, se puede reconocer más de un intento por construir formas de comunicación que se impregnan en los elementos de sostén de los edificios o que se expanden en los espacios que estos pobladores emergentes segregan. En medio de estas confrontaciones, descubrimos las características de este lenguaje arquitectónico inconcluso gestionado desde el habitar.

habitar, construir, lenguaje, significado, posmodernidad, globalización, informalidad

\section{The unfinished language of the Peruvian peripheral-neighborhood architecture. A contrast between globalization and dwelling}

Every language, including the architectural one, is created so that a linguistic group is able to share a narrative that structures a type of reality. Taking into consideration the contemporary peripheral-neighborhood architecture in Peru, this paper aims to go deeper into the current space-time coordinates in which creations will be valid, and determine the current scales of values in which dwellers of these neighborhoods prioritize their requirements and turn them into esthetic products. On that basis, more than one attempt to build forms of communication that imbue with the support elements of buildings or that expand in the spaces segregated by these emerging $d$ wellers can be recognized. In the middle of these confrontations, we discover the characteristics of this unfinished architectural language managed from dwelling.

dwelling, building, language, meaning, postmodernity, globalization, informality 


\section{INTRODUCCIÓN}

Uno de los privilegios que trae consigo el hecho de ser parte de una cultura bien consolidada es el de disponer no de una, sino de múltiples formas de lenguaje con las cuales poder acceder a los heterogéneos rostros de una misma realidad. Inducidos por las direcciones de esos derroteros, algunas verdades universales serán reveladas y otras tantas quedarán ocultas. Dice María Zambrano que "cada época se justifica ante la historia por el encuentro de una verdad que alcanza claridad en ella" (2008, p. 21). Por medio del lenguaje del arte, los pueblos de cualquier latitud y tiempo han intentado acceder a verdades tan profundas que normalmente se encuentran impedidas si se opta por seguir las rutas de lo cotidiano o de la exclusiva racionalidad.

Hasta no hace tanto tiempo, el arte se hallaba indisolublemente ligado a lo sagrado, pues se le había reconocido poder para estructurar realidades capaces de convertirse en un portal de acceso para comerciar con lo divino. Las producciones artísticas de los pueblos primitivos son, en muchos casos, intentos compulsivos por inundar su mundo material de esencia sagrada. Afirmaba el pintor Fernando de Szyszlo lo siguiente:

El hombre primitivo vivió en un cosmos sacralizado. A lo largo de toda su obra se percibe un anhelo de sacralizar el mundo, mostrándonos en cada paso su capacidad de esperar indefinidamente lo inesperado, su disponibilidad para recibirlo y el culto apasionado del enigma. (1996, p. 42)

El arte, el lenguaje que se funda desde la estética, fue advertido como el que más poder persuasivo poseía, por lo que se convirtió en aliado de las élites de turno para sentenciar verdades que se entendiesen como irrefutables. La Iglesia, las monarquías y hasta la actual dictadura del comercio globalizado pergeñaron lenguajes estéticos para que, desde su cúspide, desciendan a cualquier estrato imponiendo a su paso su ley.

La arquitectura se convirtió, desde entonces, en depositaria del lenguaje que sostenía la narrativa comunitaria del pueblo que la había erigido. Toda una simbología estructurada alcanzaba hondura al hallarse contenida al interior del espacio y del tiempo en los cuales gozaba de cordura.

Pero, a la par de este lenguaje intencionalmente elitista, coexistió siempre el lenguaje implícito del habitar, aquel que brota espontáneo de las maneras en que los individuos segregan su espacio existencial y se expanden en él. 
Figura 1. Oteando la aldea global a través de las ventanas de la contemporaneidad

Fuente: dibujo de Jessica Pastor

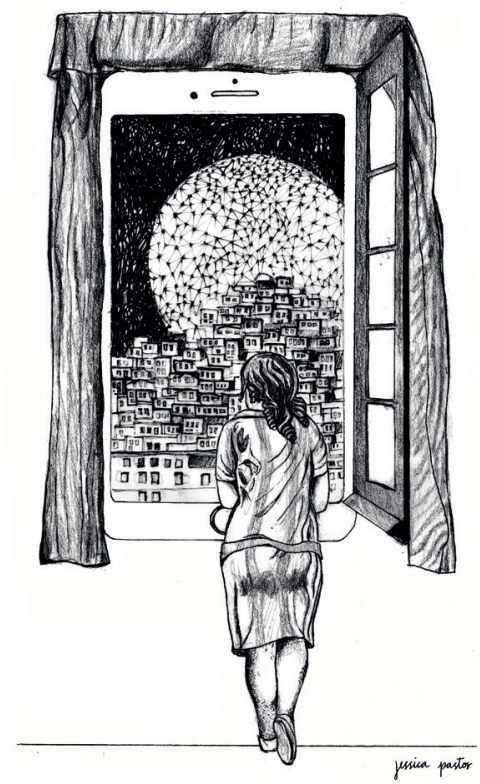

En el presente texto, se hace un llamado a develar las interpretaciones cronotópicas ${ }^{1}$ que el peruano marginal, desde sus carencias físicas, afectivas y culturales, cavila antes de edificar. También invita a reflexionar sobre la jerarquía de valores que irá delineando su derrotero cuando se decida por las pautas para construir su mundo objetual.

Los insumos que el poblador actual dispone para construir y para construirse son visiones fragmentarias de un mundo que pretende abarcarlo todo, espacios simultáneos sin materia que los contenga, tiempos tan inmediatos que solo saben desvanecerse, y valores que guardan fidelidad únicamente a las leyes del mercado. Pero una estructura mucho más persistente, la del habitar humano, tejerá una urdimbre basada en la reiteración. En los

1 Cronotópico. Del griego kronos ('tiempo') y topos ('espacio' o 'lugar'). Se utiliza para entender la percepción de la realidad que, a partir de un espacio y tiempo concordado, Ios integrantes de una cultura comparten. 
márgenes, que es donde se condensan las formas más básicas y urgentes de habitación en el Perú, empezará a brotar la narrativa más genuina sobre las maneras de segregar el espacio, expandirse en él y hacer de ello una conmemoración.

\section{LAS COORDENADAS ESPACIOTEMPORALES COMO GÉNESIS DE UNA ESTRUCTURA EXISTENCIAL}

Como todo acto de creación humana, la concreción de un lenguaje parte también del momento en que el creador reconoce las coordenadas espaciotemporales dentro de las cuales el nuevo producto gozará de validez. Esta constatación no supone un esfuerzo intelectual intencionado. Surge, más bien, a partir de un impulso natural por hacer aparente la estructura existencial en la cual los fenómenos que percibe tienen un significado concreto y se articulan en una cadena de antecedentes y sucesiones. La cultura de la cual forma parte el creador y sus congéneres es el fondo común desde donde extraerá las certezas para reconstruir un mundo acotado a su justa medida.

Las concepciones cronotópicas de las sociedades tradicionales se amparaban en la observancia de su mundo natural próximo y sus ciclos, que, con regularidad matemática, segmentaban el tiempo ordinario y el conmemorativo. La primera obligación que una cultura reconocía como urgente era proporcionar a sus miembros un espacio y un tiempo formalizado en función de una realidad afin.

Al peruano marginal, desposeído, no solo de suelo, sino de referentes concretos de territorio, no le parece mala opción volverse asiduo espectador de toda esa serie de imágenes superfluas disparadas desde cualquier pantalla virtual, que le permite frecuentar muchos sitios, pero jamás concretar un lugar.

Como todo ciudadano del siglo xxi que se guarece al interior de las burbujas virtuales que el mundo mercantil le oferta, el nuevo peruano advierte que su cuerpo ya no le es imprescindible para depositarse al interior de los límites irresueltos de estas realidades paralelas, a las que encuentra coincidentes con su necesidad de evasión. 
Lógico resultado de transitar entre una realidad y otra, los paisajes de la posmodernidad son, como describe Puente Lozano, “entornos híbridos y semióticamente redundantes, de superficies opacas, reflectantes, formadas principalmente por pantallas, con escenografias compuestas de retales y de distintos estilos arquitectónicos y dominantes por la lógica de movilidad y del consumo" (2009, p. 284). Si bien el lenguaje de los entornos emergentes en el Perú no ha llegado aún a definirse, es seguro que, al desarrollarse al interior de ese plasma global que termina por abarcarlo todo, se nutrirá de esos preceptos en donde el espacio y el tiempo son concebidos desde la simultaneidad y la inmediatez.

Cualquier forma de lenguaje creada por el hombre necesita reverberar al interior de una caja de resonancia delimitada por coordenadas espaciotemporales concretas. Cuando no hay muros que segreguen espacios ni tiempos, que marquen su cadencia, cualquier intento de comunicación termina desparramándose por los agujeros de la inmediatez.

A partir de esta realidad descompuesta en fragmentos resulta imposible construir una narrativa estable y comunitaria. Pedazos de historias individuales son probablemente la única posibilidad que encuentra el constructor para intentar engranar un todo del cual formar parte.

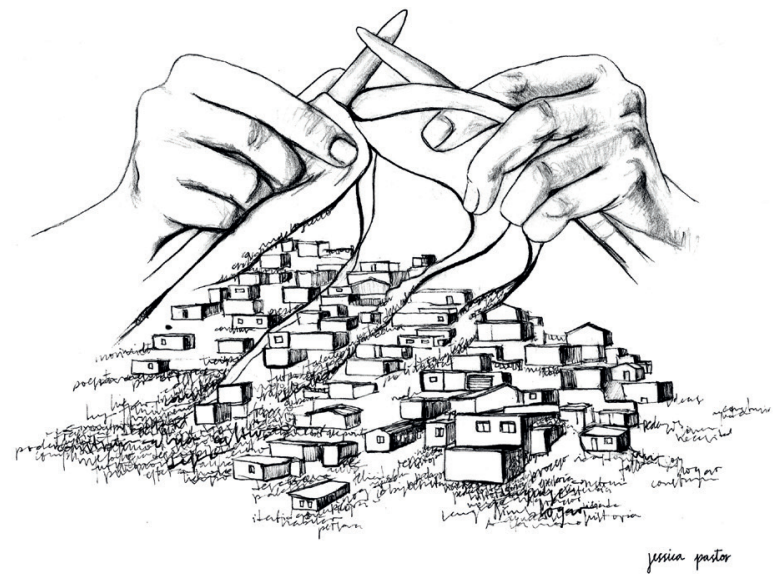

Figura 2. Tejiendo una narrativa desde el fragmento, la simultaneidad y la inmediatez

Fuente: dibujo de Jessica Pastor 


\section{EL APOSENTO DE LAS COSAS EN UNA ESCALA DE VALORES}

Todo modo de vivir, cualquier forma de ser, está siempre precedida por categorías éticas, morales y estéticas que descienden desde lo colectivo para repercutir, por adhesión o rechazo, en lo individual. A partir de estas normas, el individuo sabrá disociar lo relevante de lo banal, lo bueno de lo malo, lo genuino de lo falso.

Toda cultura antigua se sostenía en sus lealtades comunitarias, sin importar que estas fueran coincidentes con las de otros colectivos humanos. Cualquier objeto producido al interior de este mundo normado tenía cabida en una estantería de méritos que en su conjunto apilaba el mundo material, por donde los hombres se desplazaban con el sosiego que brinda la coherencia. Protegerlo era un deber y un reconocimiento tanto a su utilidad práctica como al sistema de valores que sostenía su modo de existir. Una cultura, dice Vargas Llosa (2012), está mucho más determinada por la calidad y la sensibilidad que por la cantidad de conocimientos.

Hoy en día, la frivolidad de la cultura contemporánea se evidencia en la medida que "la forma importa más que el contenido, la apariencia más que la esencia y en la que el gesto y el desplante - la representación- hace las veces de sentimientos e ideas" (Vargas Llosa, 2012, p. 37).

Desposeído de certezas y desplazado a los bordes, el habitante informal crea su escalafón de valores, delineado, en gran medida, en función de sus carencias existenciales. Ahora resultan escazas las normas que puedan sugerirle una cultura que se solaza en transgredir o tergiversar lo que hasta hace unos años la tradición recomendaba respetar.

Los valores, hoy en día, están en primer lugar en función de la novedad. Explica Chantal Maillard que

lo nuevo es valorado porque es una variante de lo distinto y lo distinto es un valor porque permite atraer la atención, lo cual es una necesidad del individuo cuando este no está determinado por una cultura tradicional que le dicta la tarea, los deberes y las relaciones, sino que ha de defenderse solo, en competitividad con otros individuos. (2009, p. 31)

El peruano marginal, alejado de las fuentes más directas de su cultura ancestral, vive padeciendo la sed por una autodefinición. Sabe, o intuye, que 
en la novedad de formalizar los objetos de su habitación terminará de darse forma a sí mismo.

En segundo lugar, los valores contemporáneos se inclinan ante las lógicas del mercado que sentencian toda ley al interior del mundo globalizado. Desde hace un buen tiempo el Perú forma parte de esa maquinaria que, para echarla a andar, tiene que percibir el bien como producto. Cualquier objeto empieza a tener una cotización en el fluctuante mercado. Incluso las manifestaciones artísticas, que hasta hace unos años se fundamentaban en la independencia, tienen que ajustarse ahora a la estética imperante de las modas. Afirman Lipovetsky y Serroy que "el consumo del componente estético ha adquirido tal relieve que constituye un factor importante de la afirmación identitaria de los individuos" (2015, p. 23). Al hacerse de un terreno, al ir construyendo su vivienda, al formalizarla, el habitante logrará ser propietario, y esto, más que cualquier otra cosa, le otorgará carta de ciudadanía en la nueva aldea global.

Desaparecida cualquier forma de utopía comunitaria que aspiraba a una transformación radical del estado de las cosas, el habitante del mundo contemporáneo no lucha por cambiar el sistema. Si se permite algún tipo de pugna será más bien para ser aceptado al interior de esa estructura social idealizada como inmejorable. Los reclamos de los grupos minoritarios no son para cambiar el sistema, sino para que se les incluya en él. Pero si el sistema funciona es, entre otras cosas, por su habilidad de proporcionar fugaces imágenes placenteras que reemplazan al antes anhelado estado de bienestar.

Es al interior de las plácidas burbujas mediáticas, insufladas desde las indispensables pantallas digitales, en donde las bases de los valores tradicionales se corroen para desplomar las antiguas estructuras culturales locales. Convertidos en fragmentos de escaza utilidad práctica, se hará uso de estas formas del pasado histórico como un recurso nostálgico que termina de concretar una realidad aparente. El tercer grupo de valores contemporáneos se encuentra, pues, tanto en la capacidad evasiva de los entornos mediáticos para suplantar una realidad muchas veces adversa como en la utilidad que cobran los fragmentos para reconstruir difusos paisajes melancólicos de un pasado desposeído de sus méritos más profundos. 


\section{LOS LENGUAJES DEL HABITAR CONDENSADOS EN LA MARGINALIDAD}

El significado que finalmente guarda la estructura fisica de cualquier habitación humana se debe, en gran medida, a la coexistencia de dos formas de lenguaje: un modo explícito y el otro implícito.

Como ya hicimos mención, el lenguaje explícito es aquel intencionado, el que aparece como consecuencia lógica de los humanos que han descubierto en el habitar no solo una forma acertada de contenerse, sino también de expandirse. La historia de la arquitectura nos da cuenta de que en muchas de sus etapas este lenguaje venía impuesto por una élite, preferentemente política o religiosa, que sabía que los edificios eran el recurso más efectivo para sentenciar los preceptos bajo los cuales quedarían incólumes las jerarquías que pretendían mantener. Ninguna de esas sociedades escatimó recursos ni prescindieron de las mentes más brillantes y sensibles para pergeñar un lenguaje artístico que, desde los edificios más encumbrados, descendiese hasta los más pueriles en ese afán de nutrir todo el mundo físico de su inapelable ley.

Sin embargo, reiteramos que el significado más cabal que uno puede hallar en un edificio resulta del enfrentamiento de este lenguaje intencionado y el que surge de los modos espontáneos en los que el ser humano se procura habitación. El lenguaje implícito es muy sensible a las condiciones particulares en que una edificación es hecha. En él se puede leer la adaptación de los elementos constructivos al medio natural donde se emplazan, así como lo distintivo del pequeño grupo que habita ese edificio. De la confrontación de estos dos modos de lenguaje en un solo plano perceptivo surgirán concordancias, desajustes, antagonismos, divergencias y, finalmente, la riqueza expresiva de la arquitectura.

\section{EL LENGUAJE EXPLÍCITO}

Modificado el orden de las cosas, ya no existe en el mundo élites globales que impongan su ley a través de un discurso simbólico con intenciones absolutistas. Las leyes que hoy nos someten —las del mercado, claro estálo hacen desde una narrativa blanda y en apariencia inofensiva, en la cual el destinatario del mensaje se siente favorecido y plácido. Alertándonos 
de ello, Chantal Maillard concluye que "se trata, pues, de proporcionar satisfacciones materiales y emocionales moderadas que consigan mantener un estado aparentemente satisfecho, pero altamente insatisfecho en las capas más profundas del espíritu" (2009, p. 36).

El lenguaje explícito que al constructor contemporáneo en el Perú seduce viene desposeído de una gramática concluyente capaz de articular la multiplicidad de sus componentes en una sola estructura. Ningún producto puede aspirar con facilidad a la armonía si se carece de partituras. En medio de las laxas redes urbanas de la informalidad, lanzadas sobre territorios aún por conquistar, el peruano emergente empieza a interpretar un lenguaje inconcluso que no hace más que subrayar el estado actual de su estadio cultural.

Habíamos ya concluido que el espacio y el tiempo que dispone el habitante de los entornos globalizados es el de la simultaneidad y la inmediatez. Excluido de muchos entornos, menos de este, el peruano marginal puede administrar referentes virtuales desde donde extrae imágenes mucho más caracterizadas por su abundancia que por la nitidez. A partir de estos fragmentos, que en muchos casos nada tienen que ver con el mundo de la construcción, el incipiente autor intentará fundar una narrativa personal que se incorpore los elementos fisicos que sostienen y segregan su habitación.

Los criterios de inclusión de los objetos e imágenes que pasarán a formar parte de su repertorio se encuentran íntimamente ligados a las jerarquías valorativas que, si bien hoy en día se entienden como individuales, están vinculadas a las de la sociedad actual.

En primer lugar, el valor de la novedad tiene que ver tanto con la necesaria alineación a un tiempo que, ni bien acoge objetos, casi a la vez los difumina como con la necesidad de distinguirse de una masa social tan homogénea que lo amenaza permanentemente con el anonimato. El segundo valor, el del mercado, es rápidamente asimilado en este lenguaje explícito del constructor peruano. Al materializar su habitar, le es imposible dejar de percibir un producto con la posibilidad de entrar en el circuito comercial. Finalmente, en los intentos explícitos de procurar un lenguaje a su habitación, el ciudadano emergente no puede excluir a todo elemento, forma o color con capacidad de devolverle un escenario artificioso de una 
realidad anhelada. Las fugaces ráfagas de placer son útiles para esconder prolongados estados de inconformidad. Mucho más importante que vivir de acuerdo con los códigos de representación social, dice Lipovetsky, es "sentir, vivir momentos de placer, de descubrimiento o de evasión" (2015, p. 23). Un abuso del gesto y de la redundancia debe ser entendido como un intento de "cargar de sentido lo que no lo tiene" (Maillard, 2009, p. 38).

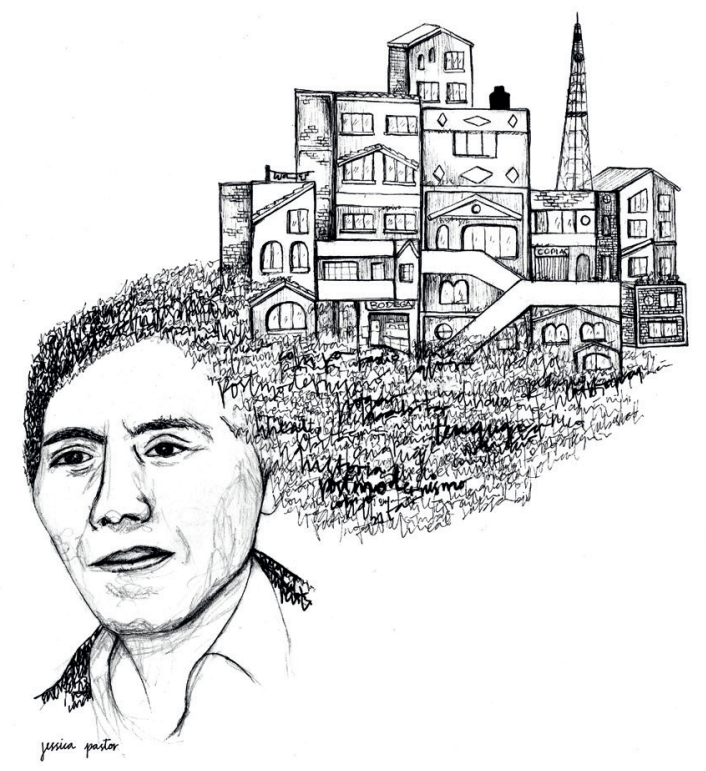

Figura 3. Carente de partituras estéticas, ningún conjunto puede aspirar a una fácil armonía formal.

Fuente: dibujo de Jessica Pastor

\section{EL LENGUAJE IMPLÍCITO}

Transformado el territorio, adaptadas las formas, superpuestas las primeras pautas de un pretendido lenguaje explícito, el edificio empieza a comportarse como un organismo que debe asumir las obligaciones de adaptarse tanto a su contexto como a los seres a los que sirve de continente. 
El habitar se concreta cuando una estructura inanimada, como es el cobijo, se funde con otra viviente, que es el hombre y sus actos. Ambas terminarán por condicionarse a causa de la coexistencia (Ríos y Zeballos, 2018). A partir de ello, otros modos de lenguaje aparecerán de manera implícita y singularizarán el edificio habitado.

A diferencia del lenguaje explícito, que se sujeta a los elementos externos de la fábrica, el lenguaje espontáneo no guarda preferencia por las fachadas. Las huellas que van dejando las actividades habituales en la materia se plasman en la esencia misma de la habitación. Así, por ejemplo, los iniciales trazos geométricos de un cuarto se modificarán en función de la acumulación y disposición de los objetos utilitarios y afectivos; espacios no previstos cobrarán un protagonismo tal que dislocarán la centralidad primitiva del hogar. La apropiación y reiterado uso del espacio hace que este se altere, se singularice y empiece a prosperar el germen de un lenguaje propio.

El lenguaje más honesto que puede derivarse de una vivienda que emerge desde la necesidad es el de los reiterados intentos, personales y familiares, de conseguir bienestar. A diferencia del placer, que, como hemos desarrollado, se empecina en la posesión puntual de lo deseado, el bienestar humano se logra en la medida que se vayan mitigando las angustias más profundas que toda persona tiene, en lapsos temporales de amplia duración.

El lenguaje implícito del habitar, que va apropiándose y reformando la materia del edificio inicial, es el de la vivencia y la convivencia en el afecto con los semejantes, es el de la coexistencia con los objetos acumulados, el de la veneración a los dioses y el de la conmemoración de los ausentes (Ríos y Zeballos, 2018). Domesticar el espacio es tornarlo doméstico, y esto es posible haciéndolo pasar por los tamices del domus, la casa. Dice el poeta Hugo Mujica:

Habitando ponemos en juego nuestros hábitos. La casa, la morada, es donde lo incierto, lo extraño, se calma reconocimiento. Las reglas son propias, son costumbres, tradición, ritos y ceremonias. Las reglas, en la casa, nos reflejan, en ellas nos encontramos. Nos reconocemos... Descansamos. (2008, p. 25) 
Figura 4. La construcción implícita del lenguaje del habitar

Fuente: dibujo de Jessica Pastor

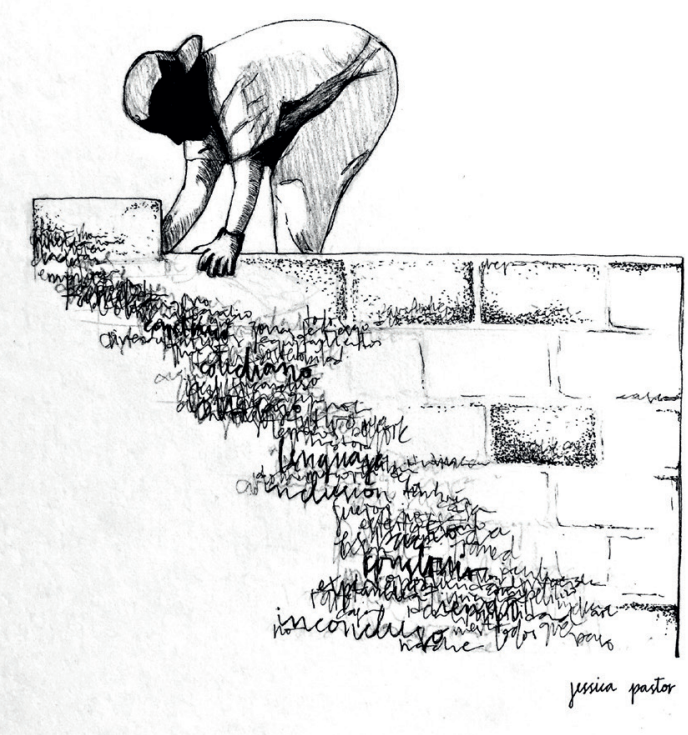

\section{LA CONFRONTACIÓN DE LENGUAJES}

Existe, pues, en esta arquitectura, más de una estructura formal. En algunos casos, se superponen; en otros, se conjugan, y en los demás, se enfrentan. Sin embargo, ninguna de ellas ha sido todavía capaz de sintetizar sus componentes como para hablar de un lenguaje concluido con la capacidad de transmitir significados homogéneos al interior de una comunidad lingüística. Si bien podemos hablar de recurrencias formales en un amplio número de unidades constructivas, terminan anteponiéndose los rasgos de la individualidad del habitante que, en la mayoría de casos, es también el creador. 
Una estética de la ambigüedad resulta fundamental para que germinen, entre las grietas de la imprecisión, los rasgos de la novedad como sello distintivo del tiempo que vivimos: el de la inmediatez. Pese a ello, no podemos dejar de reconocer la riqueza de información que, sobre el habitar contemporáneo, puede revelarse de estos organismos arquitectónicos (además, hasta el momento, solucionan de manera más urgente las necesidades de albergue en el Perú).

Es precisamente a partir de las confrontaciones, el antagonismo y las tensiones entre estas modalidades inconclusas de lenguaje que se puede advertir, de manera más categórica, los fundamentos de la arquitectura contemporánea y también los principios del habitar de todos los tiempos.

Mientras en sus intentos por concretar un lenguaje explícito en su vivienda el habitante peruano no puede sustraerse de las concepciones contemporáneas del tiempo inmediato y el espacio fragmentado, de manera implícita esa misma estructura se va modificando en función de las huellas que le deja la reiteración de sus actos de habitar. Entretanto, las formas externas quieren dar testimonio exprofeso de su adhesión a los valores del mundo globalizado y los espacios intentan adaptarse a las leyes del justo acomodo de las cosas en un pretendido bienestar.

En el ínterin en que una ornamentación se prende de las superficies, la genuina estructura del habitar se ancla a las profundidades de la realidad del hombre. Mientras que el habitar siga siendo el acto más extremo de la existencia humana, será inevitable que las formas que lo cobijan compongan una narrativa de su conciencia existencial. 


\section{REFERENCIAS}

De Szyszlo, F. (1996). Miradas furtivas. Lima: Fondo de Cultura Económica. Lipovetsky, G., y Serroy, J. (2015). La estetización del mundo. Barcelona: Anagrama.

Maillard, Ch. (2009). Contra el arte y otras imposturas.Valencia: Pre-Textos.

Mujica, H. (2008). La casa y otros ensayos. Madrid:Vaso Roto.

Puente Lozano, P. (2009).Viajes por los paisajes urbanos posmodernos. O de cómo ubicarse en medio del caos. Boletín de la Asociación de Geógrafos Españoles, (51), 275-304.

Ríos, G., y Zeballos, C. (2018). Poética de un mundo habitado. Arequipa: Universidad Católica de Santa María de Arequipa.

Vargas Llosa, M. (2012). La civilización del espectáculo. Lima:Alfaguara.

Zambrano, M. (2008). Hacia un saber sobre el alma. Madrid:Alianza Editorial. 